\title{
Update on the role of C1GALT1 in cancer (Review)
}

\author{
TONG XIA*, TING XIANG* and HAILONG XIE \\ Hunan Province Key Laboratory of Tumor Cellular and Molecular Pathology, Institute of Cancer Research, \\ School of Medicine, University of South China, Hengyang, Hunan 421001, P.R. China
}

Received November 2, 2021; Accepted January 17, 2022

DOI: $10.3892 / \mathrm{ol} .2022 .13217$

\begin{abstract}
Cancer remains one of the most difficult diseases to treat. In the quest for early diagnoses to improve patient survival and prognosis, targeted therapies have become a hot research topic in recent years. Glycosylation is the most common posttranslational modification in mammalian cells. Core 1 $\beta 1,3$-galactosyltransferase (C1GALT1) is a key glycosyltransferase in the glycosylation process and is the key enzyme in the formation of the core 1 structure on which most complex and branched O-glycans are formed. A recent study reported that C1GALT1 was aberrantly expressed in tumors. In cancer cells, C1GALT1 is regulated by different factors. In the present review, the expression of C1GALT1 in different tumors and its possible molecular mechanisms of action are described and the role of C1GALT1 in cancer development is discussed.
\end{abstract}

\section{Contents}

1. Introduction

2. C1GALT1, a glycosyltransferase

3. Molecular mechanisms of C1GALT1 in tumorigenesis

4. C1GALT1 has a tumor suppressor role in tumors

5. Clinical applications of C1GALT1

6. Conclusions

\section{Introduction}

The glycosylation of proteins is a sophisticated protein modification. Depending on the sugar-amino acid bond, glycosylation

Correspondence to: Professor Hailong Xie, Hunan Province Key Laboratory of Tumor Cellular and Molecular Pathology, Institute of Cancer Research, School of Medicine, University of South China, 28 Changsheng West Road, Steaming Xiang, Hengyang, Hunan 421001, P.R. China

E-mail: hailongxie7878@163.com

*Contributed equally

Key words: glycan, glycosylation, glycosyltransferase, core 1 $\beta 1,3$-galactosyltransferase, T-synthase may be divided into two categories: N-glycosylation and $\mathrm{O}$-glycosylation. Sugars are connected either to the amino group's lateral chain of asparagine residues (N-linked glycosylation) or, more commonly, to the hydroxyl group's lateral chains of serine (Ser) or threonine (Thr) residues (O-linked glycosylation) $(1,2)$. N-glycosylation has been well studied, but less is known about O-glycosylation. O-glycosylation is also frequently referred to as mucin (MUC)-based glycosylation, as O-glycans make up $>80 \%$ of the sugar chain (3).

$\mathrm{O}$-glycosylation is initiated in the presence of polypeptide $\mathrm{N}$-acetylgalactosamine-transferase-(GalNAc-T), which catalyzes the formation of the GalNAca1-O-Ser/Thr linkage in $\mathrm{O}$-glycoproteins. The synthesis process occurs in the Golgi apparatus (4). The addition of $\mathrm{N}$-acetylgalactosamine (GalNAc) to Ser/Thr residues forms the GalNAc $\alpha 1-S e r / T h r$ structure [also known as the Thomsen-nouvelle (Tn) antigen] (5-7). Subsequently, the Tn antigen further forms core I, II and III structures under the action of glycosyltransferases, such as core 1 1 1,3-galactosyltransferase (C1GALT1), core $2 \beta-1,6-\mathrm{N}$ acetylglucosaminyltransferase and core $3 \beta 1,3 \mathrm{~N}$-acetylglucosa minyltransferase $(7,8)$. The formation of the core 1 structure is the most frequent modification of the Tn antigen $(9,10)$.

Glycosylation is important for megakaryocyte development and platelet production in vivo (11). The pathogenesis of human tumors suggests that cells acquire a series of characteristic functions, such as maintenance of proliferation, evasion of growth inhibitors and perpetual replication, during the transition from the normal to the tumor state (12). Abnormal glycosylation affects cell adhesion, migration and proliferation (13). Glycosylation has recently been proposed to be associated with the acquisition of labeling capacity (14) and may be a biomarker of cancer (13). Based on the significance of glycosylation in the tumor pathway, the present review focuses on the key enzyme of glycosylation, C1GALT1, in tumorigenesis and therapy.

\section{C1GALT1, a glycosyltransferase}

C1GALT1 (also known as core 1 synthase or T-synthase), a glycosyltransferase with a molecular weight of $42-43 \mathrm{kDa}$, is encoded by chromosome 7p14-7p13. Analysis of the cDNA sequence of human C1GALT1 has revealed that it contains three exons (10). C1GALT1 is a mammalian cell-specific T-synthase that catalyzes the transfer of galactose (Gal) from UDP-Gal to the extant GalNAc (Gal/1, 3GalNAco-O-Ser/Thr) that forms the core 1 O-glycan (15) (Fig. 1). ClGALT1 has an important 
role in numerous biological processes and alterations in its expression may cause developmental defects and affect the malignant behavior of a tumor (16). Numerous glycoproteins have regulatory roles in the development of the lymphatic system. Knockdown of the C1GALT1 gene in endothelial and hematopoietic cells in mice causes deletion of O-glycan chains in endothelial cells of blood vessels and lymphatic vessels, resulting in disruption of vascular-lymphatic connections and fatty liver (17). C1GALT1 is abnormally expressed in a variety of malignant tumor types, including pancreatic cancer (18), gastric cancer (19), head and neck squamous cancer (20), laryngeal cancer (21), ovarian cancer (22) and liver cancer (23). In summary, C1GALT1 has an important role in maintaining normal physiological functions and also participates in the development of tumors.

ClGALT1 and Tn antigen. Synthesis of the Tn antigen is the first step in the initiation of O-glycosylation; under normal conditions, GalNAc is first added to serine/threonine via an $\alpha$-bond to form Tn antigen, and then galactose is transferred to Tn antigen via a $\beta$-glycosidic bond with the aid of C1GALT1 to form core 1-O glycans. However, in the absence of C1GALT1, $\mathrm{Tn}$ antigen is not properly converted to $\mathrm{T}$ antigen, resulting in overexpression of $\mathrm{Tn}$ antigen, followed by increased expression of sialyl-Tn antigen (sTn antigen) in the presence of increased Tn (24). Tn antigen and sTn antigen are expressed in numerous types of tumor, including colon, lung, cervical, ovarian, prostate and gastric cancers. The expression of Tn antigen and sTn antigen is positively associated with metastasis and poor prognosis of patients (25-27). In addition, Tn or sTn antigen expression is also present in the hinge region of $\operatorname{IgA} 1$ molecules in patients with $\operatorname{IgA}$ nephropathy as a result of abnormal O-glycosylation of IgA1 (28).

ClGALT1 and Cosmc. Cosmc (or C1GALT1C1) is a unique molecular chaperone essential for mammalian C1GALT1 $(6,29)$. Similar to T-synthase, Cosmc was first purified from rat liver and its molecular weight is similar to that of T-synthase at 36-38 KDa according to SDS-PAGE analysis (7). Cosmc is located on chromosome Xq24 and includes one encoding exon of $\sim 1 \mathrm{~kb}$ and it has 26 homologous sequences to C1GALT1 (30), which maintains the stability and folding of C1GALT1 in the endoplasmic reticulum (29).

Human T-leukemia Jurkat cells produce truncated O-glycan (Tn antigen) due to deficiency of T-synthase activity (31). The gene and transcript level of T-synthase are normal in Jurkat cells, but a $\mathrm{T}$ deletion is present at nucleotide position 478 in the Cosmc cDNA sequence, causing early appearance of the stop codon (6). However, the addition of wild-type Cosmc restores T-synthase activity and the normal extension of O-glycan $(6,32)$. Cosmc is involved in the cotranslation of C1GALT1 and hinders the unfavorable clustering of C1GALT1 (29). In the absence of Cosmc, inactivated T-synthase accumulates and translocates from the endoplasmic reticulum back into the cytoplasm where it is degraded in a ubiquitin-/proteasome-dependent manner (33). However, Cosmc may reactivate the activity of denatured T-synthase (34). Molecular chaperones bind to non-natural proteins but not to natural proteins, forming stable complexes that result in efficient folding (35). Regarding the combination of Cosmc with unnatural C1GALT1, Ju et al (36) indicated that Cosmc does not affect natural T-synthase but forms stable complexes with unnatural T-synthase. Cosmc therefore provides a novel mechanism for regulating protein O-glycosylation. Several studies have indicated that Cosmc mutations cause C1GALT1 defects, resulting in $\mathrm{Tn}$ antigen exposure across multiple blood cell lineages to form Tn syndromes (37).

\section{Molecular mechanisms of C1GALT1 in tumorigenesis}

C1GALT1 expression is upregulated in most tumors. Numerous studies have indicated that C1GALT1 overexpression is closely associated with the malignant behavior of tumors, which involves multiple steps, including proliferation, invasion, tumor spread and immune evasion (38). In addition, C1GALT1 expression is associated with poor patient prognosis (39-41). To better analyze the role of C1GALT1 in tumors, the molecular mechanisms by which C1GALT1 exerts a regulatory role in cancer are discussed (Table I; Fig. 2).

\section{Upstream regulators of CIGALT1}

MicroRNA (miRNA/miR)-181d-5p. miRNAs are a class of small noncoding RNAs that regulate gene expression at the posttranscriptional level (42). miRNAs are involved in numerous cellular processes, including cell growth, development, differentiation and apoptosis $(43,44)$. miR-181d-5p has been reported to affect tumorigenesis and malignant transformation in different signaling pathways $(45,46)$. Of note, miR-181d-5p has been indicated to have an oncogenic role in non-small-cell lung cancer (47). Similarly, in lung adenocarcinoma (LUAD), the overall survival rate of patients with low miR-181d-5p expression was lower than that of patients with high miR-181d-5p expression. On this basis, Dong et al (48) indicated that miR-181d-5p was able to bind to the C1GALT1 $3^{\prime}$ UTR and act as an inhibitor of proliferation, migration and invasion of LUAD cells.

miR-152. miR-152 has also been reported to exhibit aberrant expression in a variety of malignancies (49-51). Dong et al (52) indicated that in gastric cancer, miR-152 is an upstream regulator of C1GALT1 and able to negatively regulate C1GALT1 expression by binding to the C1GALT1 3'-UTR. Overexpression of miR-152 decreased C1GALT1 expression, while downregulation of miR-152 increased C1GALT1 expression. They also demonstrated that the promoting effect of C1GALT1 on the growth and metastasis of gastric cancer was associated with miR-152.

\section{Downstream regulators of ClGALT1}

Rac family small GTPase 1 (RACl). The Rho family of small GTPases has been identified as an important signaling effector in the regulation of cellular morphology and motility. RAC1 is a member of the Rho family of small GTPases (53) and is involved in cellular activities, such as phagocytosis, adhesion, migration, motility and proliferation (54). In recent years, RAC1 has been reported to be involved in numerous physiological and pathological processes, including cancer (55). Aberrant expression of RAC1 is considered a hallmark of cancer and increases the tumorigenic and metastatic properties of cancer cells (56). There is increasing evidence that 


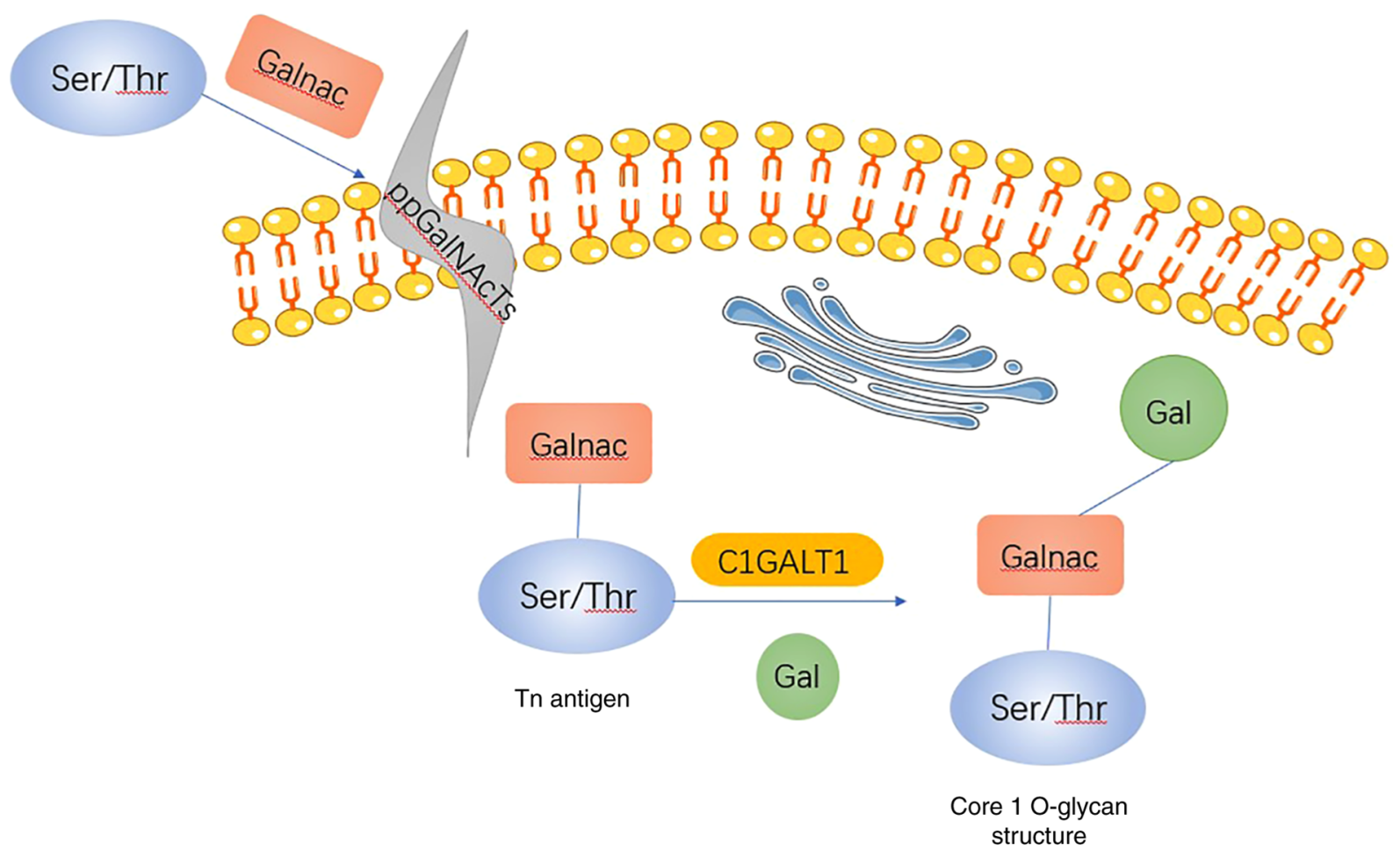

Figure 1. In the presence of GalNAc transferase, serine/threonine residues form a GalNAc $\alpha 1$-Ser/Thr structure (also known as Tn antigen) with GalNAc, followed by C1GALT1-catalyzed transfer of Gal from UDP-Gal to the existing Tn antigen to form a core 1 O-glycan structure. Gal, galactose; GalNAc, N-acetylgalactosamine; Tn, Thomsen-nouvelle; C1GALT1, core 1 1 1,3-galactosyltransferase.

different factors may affect RAC1 expression. For instance, lncRNA NR2F2AS1 overexpression promoted Rac1 expression in clear cell renal cell carcinoma (57), knockdown of RhoGDI 2 decreased the mRNA expression of Rac1 in gastric cancer (58) and knockdown of DDX3 decreased the expression of RAC1 protein in medulloblastoma (59). De et al (55) indicated that the Rho GTPase signaling pathway is closely related to C1GALT1 expression, while RAC1 is a driver of tumor growth and metastasis. They further reported that RAC1 is positively regulated by C1GALT1 in LUAD, as high expression of C1GALT1 increased RAC1 expression, while low expression of C1GALT1 decreases RAC1 expression. Furthermore, knockdown of RAC1 reversed the oncogenic effect induced by C1GALT1 (48).

Receptor tyrosine kinase (RTK) signaling pathway Ephrin receptor A2 (EPHA2). RTKs, such as epidermal growth factor receptors (EGFRs), fibroblast growth factor receptor 2 (FGFR2) and MET, have been reported to carry O-glycans $(23,60-63)$. O-glycosylation is involved in the phosphorylation of various RTKs such as EGFR, FGFR2 and MET $(20,23,60)$. Evidence suggests that RTKs actively contribute to gastric carcinogenesis and disease progression and are considered targets for cancer therapy $(64,65)$. Ephrin receptors are the largest family of RTKs and affect a variety of developmental processes (66). The human ephrin receptor is composed of EPHAs and five EPHBs that preferentially bind their respective ephrin A and B ligands. Ephrin receptors are highly expressed in cancer and promote tumor development (67-70). Therefore, EPH receptors are considered to be attractive targets for tumor therapy $(67,71,72)$. EPHA2 and its ligand ephrin A1 are highly expressed in gastric adenocarcinoma and overexpression of EPHA2 is associated with poor prognosis $(73,74)$. Yuan et al $(75)$ reported that C1GALT1 is highly expressed in gastric adenocarcinoma and that overexpression of C1GALT1 promotes malignant behavior in gastric cancer cells. C1GALT1 modifies the O-glycan on EPHA2 and regulates soluble ephrin A1-induced tyrosine phosphorylation of EPHA2, and silencing EPHA2 results in inhibition of gastric cancer cell growth and invasion. Knockdown of EPHA2 had no significant effect on cell viability but EPHA2 knockdown diminished cell migration and invasion. By contrast, high expression of C1GALT1 increased the tyrosine phosphorylation of EPHA2, promoted the binding of ephrin A1 to the cell surface and further enhanced soluble ephrin A1-induced migration of gastric cancer cells (19).

MET. RTKs are reported to have an important role in the proliferation of hepatocellular carcinoma (76,77). Previous studies focused on the effect of N-glycans on RTK, but in recent years, it has been indicated that $\mathrm{O}$-glycosylation is also able to modulate their activity $(62,78)$. In hepatocellular carcinoma, MET signaling is aberrantly activated when cell proliferation is abnormally enhanced (79-81). Hepatocyte growth factor (HGF)/MET signaling has been indicated to promote the invasion and metastasis of hepatocellular carcinoma cells $(82,83)$. Wu et al (23) reported that C1GALT1 was highly expressed in hepatocellular carcinoma cells and that overexpression of C1GALT1 enhanced the proliferation of hepatocellular carcinoma cells, whereas knockdown of C1GALT1 resulted in inhibition of the proliferation of hepatocellular carcinoma cells in vitro and in vivo. In addition, C1GALT1 modified the 
Table I. Regulatory factors that interact with C1GALT1 in different types of tumor.

\begin{tabular}{|c|c|c|c|c|c|}
\hline $\begin{array}{l}\text { Regulating } \\
\text { factor }\end{array}$ & Tumor type & $\begin{array}{l}\text { Upstream or } \\
\text { downstream of } \\
\text { C1GALT1 }\end{array}$ & $\begin{array}{l}\text { Regulation } \\
\text { method }\end{array}$ & Biological function & (Refs.) \\
\hline Integrin $\beta 1$ & Hepatocellular carcinoma & Downstream & $(+)$ & $\begin{array}{l}\text { Low expression inhibits cell } \\
\text { adhesion, migration and invasion }\end{array}$ & (5) \\
\hline EPHA2 & Gastric cancer & Downstream & $(+)$ & $\begin{array}{l}\text { Low expression inhibits growth } \\
\text { and invasion }\end{array}$ & (19) \\
\hline EFGR & $\begin{array}{l}\text { Head and neck squamous } \\
\text { carcinoma }\end{array}$ & Downstream & $(+)$ & & (20) \\
\hline miR-181d-5p & Lung adenocarcinoma & Upstream & $(-)$ & $\begin{array}{l}\text { Inhibition of proliferation, } \\
\text { migration }\end{array}$ & (48) \\
\hline RAC1 & Lung adenocarcinoma & Downstream & $(+)$ & $\begin{array}{l}\text { Low expression inhibits tumor } \\
\text { growth and metastasis }\end{array}$ & (48) \\
\hline miR-152 & Gastric cancer & Upstream & $(-)$ & & (52) \\
\hline Integrin $\alpha 5$ & Gastric cancer & Downstream & $(+)$ & $\begin{array}{l}\text { Low expression inhibits tumor } \\
\text { cell adhesion and migration }\end{array}$ & (52) \\
\hline FGFR2 & Colon cancer & Downstream & $(+)$ & & (60) \\
\hline MET & Hepatocellular carcinoma & Downstream & $(+)$ & & $(82,83)$ \\
\hline Integrin $\alpha v$ & $\begin{array}{l}\text { Pancreatic ductal } \\
\text { adenocarcinoma }\end{array}$ & Downstream & $(+)$ & $\begin{array}{l}\text { Low expression inhibits cell } \\
\text { invasion }\end{array}$ & $(112,113)$ \\
\hline MUC1 & $\begin{array}{l}\text { Breast cancer, esophageal } \\
\text { squamous carcinoma }\end{array}$ & Downstream & $(+)$ & & $(116,126)$ \\
\hline
\end{tabular}

(-), negative regulation; (+), positive regulation; C1GALT1, core 1 $\beta 1$,3-galactosyltransferase; miR, microRNA; RAC1, Rac family small GTPase 1; EPHA2, ephrin receptor A2; FGFR2, fibroblast growth factor receptor 2; EGFR, epidermal growth factor receptor.

O-glycan chain of MET in RTK in hepatocellular carcinoma; low expression of C1GALT1 inhibited HGF-mediated phosphorylation of MET kinase, whereas overexpression of C1GALT1 enhanced the phosphorylation of MET (23). Receptor dimerization is a key regulatory step of RTK signaling and C1GALT1 is likely to regulate MET activity by enhancing its dimerization (84). The proliferative effect of C1GALT1 on hepatocellular carcinoma cells may be achieved by regulating MET glycosylation and dimerization (23).

FGFR2. FGFR2 and its isoforms are overexpressed in colorectal cancer and are involved in tumor growth, metastasis and angiogenesis (85). C1GALT1 is highly expressed in colorectal cancer; it enhances the proliferation, migration, invasion, sphere formation and tumor growth, as well as the metastatic potential of colorectal cancer cells, and affects patient prognosis. It has been reported that, when FGFR2 undergoes N-glycosylation, its N-glycan chain affects FGFR2 activation and intracellular transport (86). Hung et al (60) reported that C1GALT1 was able to regulate the O-glycan chain structure on FGFR2 in colon cancer cells, which suggests that FGFR2 carries short O-glycan chains, such as $\mathrm{Tn}$ and $\mathrm{T}$ antigen, in colon cancer cells. Furthermore, high expression of C1GALT1 promoted the phosphorylation of FGFR2 and the downstream signaling molecules ERK1/2. By contrast, low expression of C1GALT1 reduced the phosphorylation of FGFR2 and ERK1/2. Promotion of malignant behavior of colon cancer cells by high C1GALT1 expression may be achieved by altering the O-glycosylation and activity of FGFR2, while low C1GALT1 gene expression suppresses these malignant properties both in vitro and in vivo (60).

$E F G R$. The extracellular structural domain of EGFR is composed of four subregions, namely structural domains I, II, III and IV, where structural domains I and III are responsible for ligand binding (87). EGFR is overexpressed in head and neck squamous cell carcinoma (HNSCC) and its signaling pathway has an important role in cell proliferation and invasion (88). C1GALT is highly expressed in HNSCC and contributes to malignant behaviors such as increased cell proliferation, migration and invasion. Of note, Lin et al (20) reported that EGFR structural domain III carries an O-polysaccharide and that C1GALT1 regulates the O-glycan chain on EGFR. Low expression of the C1GALT1 gene blocks the extension of the O-glycan chain on EGFR, reduces the EGF-EGFR binding affinity, inhibits EGFR signaling and acts as a suppressor of malignant behavior (20). In prostate cancer cells, C1GALT1 regulates EGFR O-glycosylation to enhance galectin-4-mediated EGFR phosphorylation. When the C1GALT1 gene is lowly expressed, it decreases galectin-4-mediated EGFR phosphorylation but not ligand-mediated EGFR phosphorylation and downregulates EGFR protein levels (89). By contrast, in HNSCC cells, low expression of the C1GALT1 gene reduces EGF-mediated phosphorylation of EGFR without affecting EGFR protein levels. The differential effect of C1GALT1 on EGFR in prostate and 


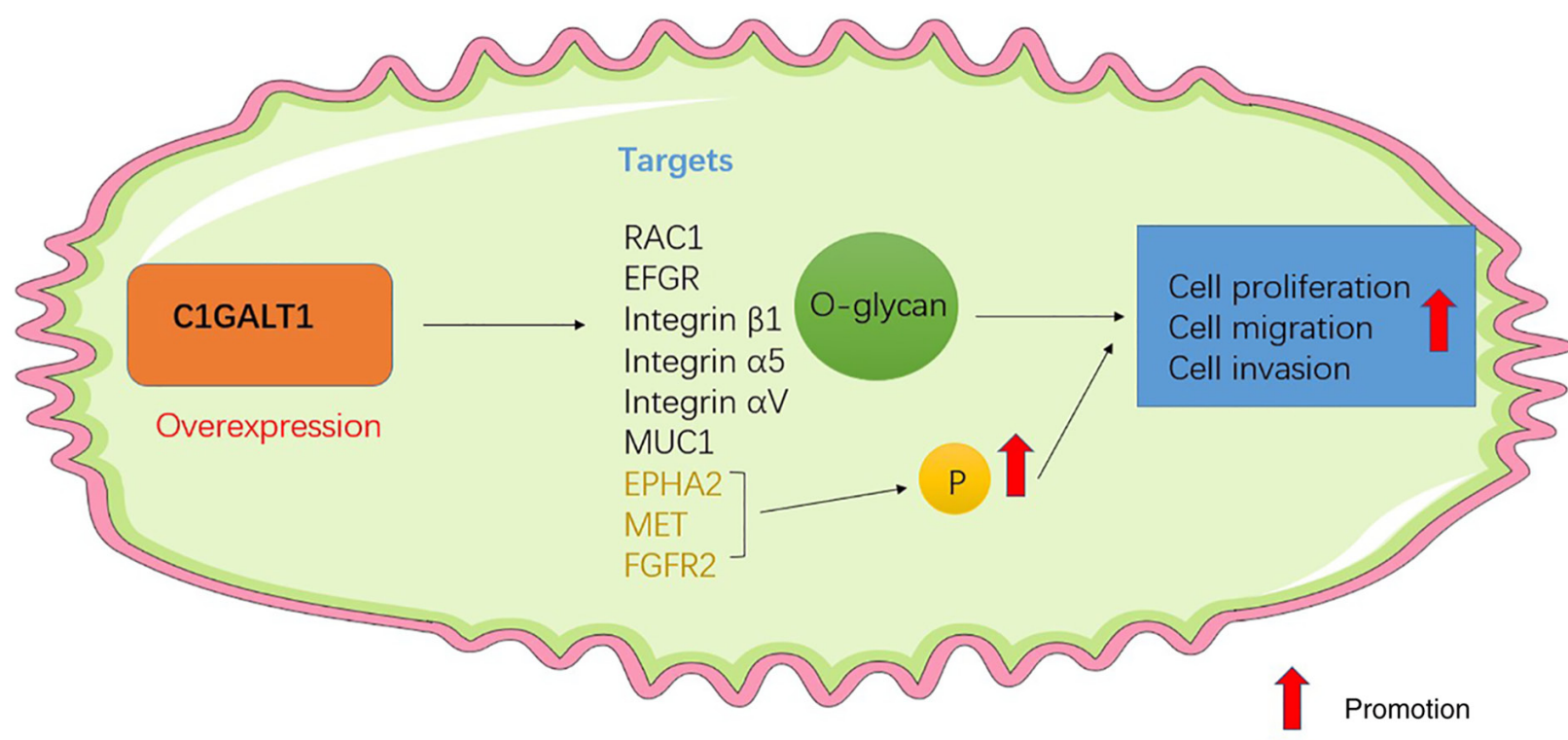

Cancer cell

P Phosphorylation

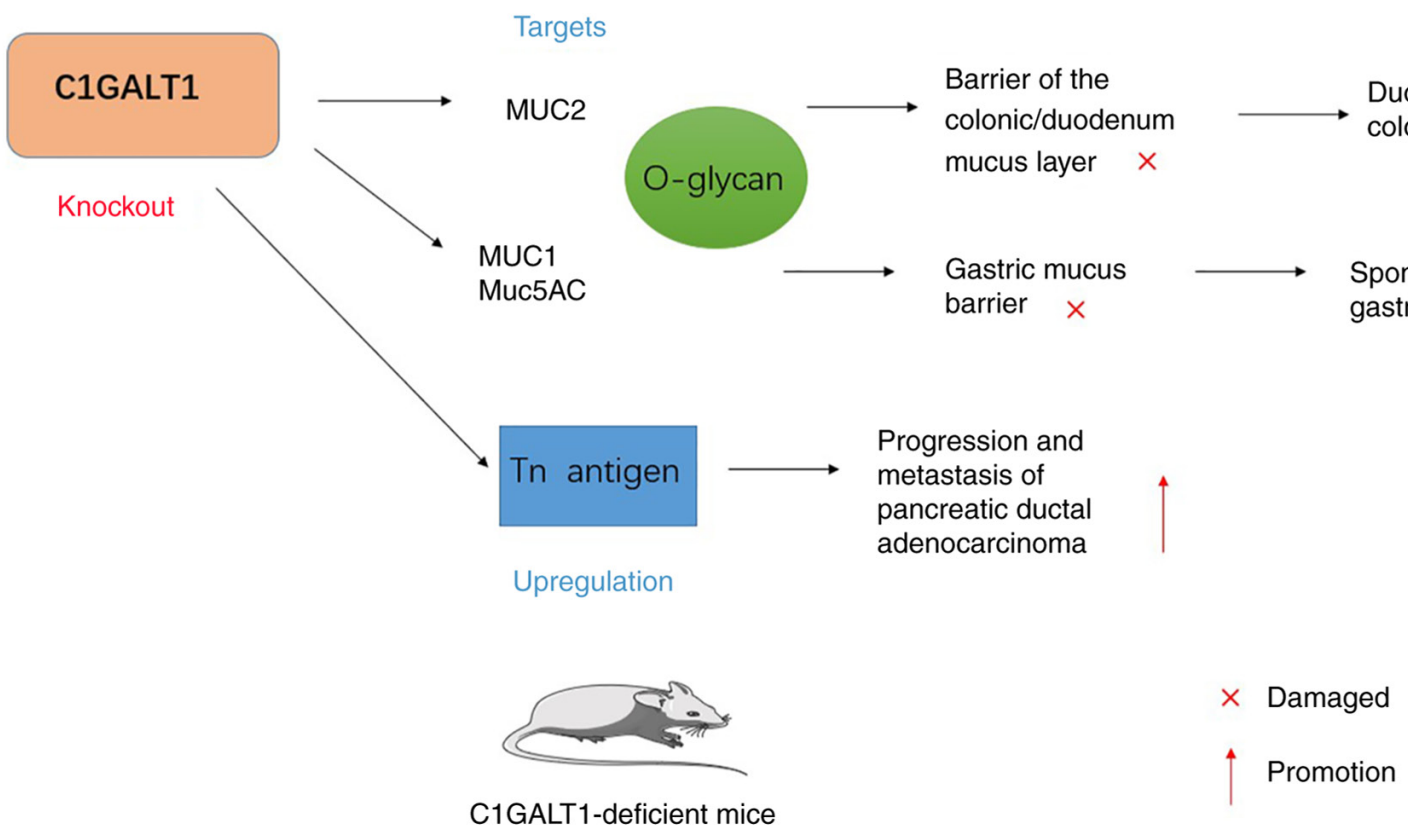

Figure 2 High expression of C1GALT1 in cancer cells promotes malignant tumor behavior; however, low expression of C1GALT1 in the constructed C1GALT1-knockout mice resulted in increased tumorigenicity in mice. MUC, mucin; Tn, Thomsen-nouvelle; C1GALT1, core 1 $\beta 1,3$-galactosyltransferase.

HNSCC cells may be due to cell-specific O-glycan groups on EGFR (20).

\section{Integrin-focal adhesion kinase (FAK) signaling pathway} Integrin $\beta 1$. Changes in the interaction between cancer cells and extracellular matrix (ECM) in the tumor microenvironment contribute to the metastasis of cancer cells (90-93). ECM receptors, such as integrins, are involved in cellular interactions with the ECM, are strongly associated with malignant tumorigenesis and have emerged as targets for cancer therapy $(91,93)$. In addition, integrins have been suggested to be key factors in the invasion of hepatocellular carcinoma cells (94-96). It has been reported that integrin $\beta 1$ is an O-glycosylated protein (97-99). Various studies have highlighted the critical nature of glycosyltransferases on ECM interactions through modification of integrins (100-103). Liu et al (5) indicated that C1GALT1 is overexpressed in hepatocellular carcinoma cells. C1GALT1 modifies the O-glycan on integrin $\beta 1$, and the promotion of cell adhesion, migration and invasion by C1GALT1 was significantly attenuated by the use of integrin $\beta 1$ blockers in high C1GALT1-expressing cells. By contrast, in cells with low C1GALT1 expression, these C1GALT1-induced malignant phenotypes were not further inhibited by integrin $\beta 1$ blockers. In addition, C1GALT1 also affects FAK, a downstream signal of integrin $\beta 1$. This indicates that C1GALT1 may regulate the malignant behavior of hepatocellular carcinoma cells by regulating the integrin $\beta 1$ signaling pathway (5).

Integrin $\alpha 5$. Integrins consist of a large family of $\alpha \beta$ heterodimeric transmembrane adhesion receptors that 
regulate adhesion, survival and motility by activating multiple intracellular signaling molecules and reorganizing the actin cytoskeleton $(104,105)$. It also has $\mathrm{N}$ - and O-linked glycosylation sites (106). Integrin $\alpha 5$ is involved in cancer development and progression by promoting tumor cell adhesion and migration through the activation of FAK (107-109). Integrin $\alpha 5$ is also an upstream regulator of the PI3K/AKT pathway and Wang et al (110) determined that integrin $\alpha 5$ is a downstream target of C1GALT1 in gastric cancer; low expression of C1GALT1 inhibited, while high expression of C1GALT1 promoted the activation of the PI3K/AKT pathway. Of note, the effects of high C1GALT1 expression on the malignant behavior of tumor cells in gastric cancer, such as proliferation, migration and invasion, were suppressed by low expression of integrin $\alpha 5$ (52).

Integrin $\alpha v$. Pancreatic ductal adenocarcinoma (PDAC) is the most common type of pancreatic cancer with abundant interstitial matrix, mainly ECM proteins, regulating tumor growth and metastasis (111). Kuo et al (18) indicated that C1GALT1 was overexpressed in PDAC and that overexpression of C1GALT1 promoted tumor migration and invasion. By contrast, low expression of the C1GALT1 gene diminished cell proliferation, migration and invasion and inhibited tumor growth and metastasis (18). In addition, low expression of the C1GALT1 gene resulted in upregulation of Tn antigen expression on integrins $\alpha \mathrm{v}$ and $\alpha 5$ in PDAC cells, accompanied by reduced cell-ECM adhesion and phosphorylation of FAK, the most important downstream signaling molecule of integrins $(112,113)$. FAK is a key downstream signaling molecule of integrins and is involved in the invasion of numerous cancer types (113-115). Of note, antibody-mediated knockdown of integrin $\alpha v$ significantly inhibited C1GALT1-mediated invasiveness of PDAC. This suggests that integrin $\alpha \mathrm{v}$ carries O-glycan chains and that C1GALT1-mediated O-glycosylation regulates integrin $\alpha v$ function (18).

MUC1- $\beta$-catenin signaling pathway. MUC1 is a large transmembrane glycoprotein consisting of a highly glycosylated extracellular portion and a small cytoplasmic tail; it is a marker of poor prognosis and a potential therapeutic target (116-118). MUC1 is a type I transmembrane mucin that contains two subunits, MUC1-N and MUC1-C (119). MUC1 is expressed in almost all epithelial tissues of the respiratory, gastrointestinal, genitourinary and hepatobiliary tracts. High expression of MUC1 has been frequently associated with tumor progression and poor prognosis in colon, breast, ovarian, lung, prostate and pancreatic cancers, which has led to the emergence of $\mathrm{MUC1}$ as a major direction for oncology treatment. Aberrant glycosylation of MUC1 is observed in cancer. This is due to the N-terminus of MUC1 containing a Variable Number Tandem Repeat segment, which contains Ser and Thr residues that may be involved in O-glycosylation binding (120-122). Core 1 glycans on MUC1 increase the degradation and accumulation of MUC1 (123). It has been reported that C1GALT1 is overexpressed in breast cancers and contributes to the enhanced invasive and migratory potential of tumors by modifying the O-glycan chain structure on MUC1, prompting increased detachment of the MUC1-N subunit from the membrane and activating the ERK phosphorylation level downstream of
MUC1-C in breast cancer cells (16). MUC1 is able to regulate the Wnt signaling pathway by forming an intracellular complex with $\beta$-catenin, which in may turn synergistically activate cyclin D1 expression in the nucleus, ultimately promoting tumorigenesis by allowing cancer cells to avoid apoptosis (124). In addition, in pancreatic cancer, it has also been indicated that MUC1 glycosylation affects the invasiveness of pancreatic cancer cells (125). Wang et al (126) demonstrated that both MUC1 and C1GALT1 were highly expressed in esophageal squamous carcinoma and were positively correlated. Furthermore, C1GALT1 was determined to affect the survival and prognosis of patients with esophageal cancer by regulating the O-glycosylation of MUC1 (126). Abnormal MUC1 glycosylation may cause shortening of glycans such as the Tn antigen, leading to hidden antigen exposure; hidden antigens usually have peptide and carbohydrate properties that make MUC1 antigen epitopes tumor-specific (127). Transgenic T cells with the MUC1-Tn chimeric antigen receptor have been reported to be therapeutically effective in xenograft models of T-cell leukemia and pancreatic cancer (128). Based on this, Kato et al (129) screened an antibody specifically against the MUC1-Tn antigen epitope carrying the Tn antigen for study in LUAD; they indicated that the antibody identified by the MUC1-Tn epitope was highly specific for LUAD cells and that high expression of MUC1-Tn was present in LUAD, but not in normal lung tissue. Antibodies specific for MUC1-Tn epitopes are expected to be novel targets for LUAD therapy (129).

\section{C1GALT1 has a tumor suppressor role in tumors}

In the colorectum, C1GALT1 is essential for the formation of an important mucus barrier in the gastrointestinal tract. MUC2 is an important mucin involved in the formation of major gels of the intestine (130-132). MUC2 has a barrier-stabilizing role for the microbiota by forming an internal tissue adhesion layer with the assistance of O-glycans (133). In a mouse model of core 1 - and core 3 -derived $\mathrm{O}$-glycan deficiency (C1galt1 ${ }^{-{ }^{--}}$; $\left.\mathrm{C} 3 \mathrm{GnT}^{-/}\right)$, Bergstrom et al $(134,135)$ observed that core 1- and 3-derived O-glycan deletion causes microbial-dependent colitis as well as severe colitis-associated cancers by reducing their stability to bacterial-derived proteases, disrupting the barrier capacity of the colonic mucus layer and activating epithelial-mesenchymal transition. It is also accompanied by rapid degradation of MUC2 and loss in the lumen, loss of mucus in the duodenal lumen and disruption of homeostasis within the duodenal mucosa, which triggers duodenal cancer (136).

In addition, O-glycans are also major components of gastric mucins, including the membrane-bound MUC1 and the mucin Muc5AC, which is involved in gastric gel formation (137). In mice with deletion of gastric epithelial O-glycan (GEC C1galt1 ${ }^{-/}$), Liu et al (15) determined that those GEC $\mathrm{Clgalt1}^{-/-}$mice develop severe spontaneous chronic gastritis in the gastric sinus first and then progress to spontaneous gastric cancer with abnormal expression of Muc5AC and Muc1. They suggest that this is caused by casp1/11, a mucosal inflammatory vesicle similar to that of the colon (15).

Dysregulation of C1GALT1 activity causes increased expression of truncated $\mathrm{O}$-glycans, and such high expression of truncated O-glycan structures (e.g., Tn and sTn) are observed 
in PDACs. To investigate the effect of truncated O-glycans on PDACs, Chugh et al (138) further established a C1GALT1 knockout mouse model based on the constructed pancreatic tumor microenvironment (Kras and p53 mutations) and observed that C1GALT1 knockout together with Kras and p53 mutations accelerated the progression of pancreatic cancer and shortened overall survival. In addition, glycosylation affects the molecular weight of the protein and the molecular weight of the highly glycosylated mucin MUC16, which is bound to the membrane in PDAC, was indicated to decrease with the loss of C1GALT1. This was accompanied by activation of the MUC16/EFGR//FAK signaling pathway, which led to increased expression of the mesenchymal markers Slug, Snail and Vimentin and decreased expression of epithelial markers such as E-cadherin and Claudin-1, increasing the metastasis of PDAC (Fig. 2) (138).

\section{Clinical applications of C1GALT1}

Radiotherapy is an effective route for tumor treatment but radioresistance remains a major obstacle to tumor outcomes. Several studies have indicated that altered glycosylation is associated with the acquisition of a multidrug-resistant phenotype (139-141). Of note, reports suggested that numerous patients present with abnormal glycosylation when they are resistant to radiotherapy $(21,142-145)$. Therefore, discovering the cause of the abnormalities that cause glycosylation is essential to increase radiosensitivity. After constructing intrinsically radiation-resistant (Hep-2max) and radiation-sensitive (Hep-2min) cell lines of the parental laryngeal carcinoma Hep-2 cell line, Dong et al (21) determined that the intrinsically radiation-resistant cell line Hep-2max had a higher content of core-type O-glycan chains than the radiation-sensitive cell line Hep-2max. By contrast, C1GALT1 modified O-glycan chains on Hep-2max and Hep-2min cells and high expression of C1GALT1 promoted the malignant behavior of laryngeal cancer cells. Furthermore, high expression of C1GALT1 was associated with increased tumor radioresistance, while knockdown of C1GALT1 increased tumor radiosensitivity. In addition, blocking integrin $\beta 1$ attenuated the radioresistance induced by high C1GALT1 expression, suggesting that C1GALT1 radioresistance to laryngeal cancer cells may be associated with integrin $\beta 1$ (21). Zhang et al (146) indicated that C1GALT1, a key enzyme in the glycosylation process, has an important role in the radioresistance of esophageal cancer. Esophageal cancer cells exhibiting high expression of C1GALT1 evaded cell death and had increased resistance to radiotherapy. Low expression of C1GALT1 resulted in reduced resistance to radiotherapy of esophageal cancer cells (146). Radiation promotes the invasive potential of certain cancer cells (147). For instance, an increase in radiation-induced invasiveness has been observed in breast cancer (148), as well as increased invasiveness of cancer cells after radiotherapy in pancreatic cancer (149). In esophageal cancer, irradiation by X-rays elevated C1GALT1 and core O-glycan expression in esophageal cancer cells and enhanced invasion, while knockdown of C1GALT1 diminished the invasive effect of irradiation on esophageal cancer cells. Normal transduction of FAK signaling downstream of $\beta 1$-integrin facilitated cell proliferation and survival and correlated with the radioresistance of cancer cells (150). In esophageal squamous carcinoma cells with C1GALT1 knockdown, the phosphorylation level of FAK was reduced. Pretreatment with a FAK inhibitor promoted radiation-induced apoptosis in esophageal squamous carcinoma cells. It was demonstrated that the anti-radiation regulation of C1GALT1 in esophageal cancer cells was achieved by affecting O-glycosylated C1GALT1 in $\beta 1$-integrin, which in turn affected the $\beta 1$-integrin/FAK signaling pathway (146). Itraconazole is a common antifungal drug with anticancer and antiangiogenic effects $(151,152)$. In HNSCC, Lin et al (20) indicated that itraconazole was able to directly interact with C1GALT1 and promote its proteasomal degradation, resulting in reduced C1GALT1 expression in HNSCC cells but not C1GALT1 mRNA expression, suggesting that the effect of itraconazole on C1GALT1 protein levels may be achieved through posttranslational modifications. In SAS cells, itraconazole acted as a C1GALT1 inhibitor and partially reversed C1GALT1-mediated effects on malignant behavior and EFGR activity in HNSCC cells. In addition, erlotinib and lapatinib also inhibited C1GALT1-mediated tumor cell viability and malignant behavior $(19,20)$.

\section{Conclusions}

C1GALT1, a key enzyme for O-glycosylation, is receiving much attention. Recent oncological research has focused on the role of C1GALT1 in tumor development. C1GALT1 is considered a biomarker and potential therapeutic target for cancer diagnosis and prediction of prognosis. The present article reviewed the currently known mechanisms of action of C1GALT1 on the malignant behavior of cancer cells and provided a theoretical basis for its potential clinical role in cancer diagnosis and prognosis determination. The dual regulatory roles of C1GALT1 in tumors may be divided into roles of oncogenesis and tumor suppression. Its role in oncogenic effects is mainly reflected in three pathways. First, miR-181d-5p and miR-152 negatively regulate C1GALT1 to exert oncogenic effects. Furthermore, deletion of C1GALT1 triggers spontaneous gastric and duodenal cancers by disrupting the major mucus barrier of the gastrointestinal tract. In addition, loss of C1GALT1 elevates truncated Tn antigen expression, contributing to higher tumorigenic and metastatic potential. By contrast, C1GALT1 achieves procancer effects by modifying the O-glycans of downstream targets. Lapatinib, erlotinib and itraconazole, as C1GALT1 inhibitors, are able to exert anticancer effects by blocking the malignant effects of C1GALT1 in cancer cells.

However, most studies currently focus only on the predictive and poor prognostic value of high C1GALT1 expression with cancer, but continued research is required to determine whether there is consistency in its mechanism of action in different tumor types. Furthermore, based on the cancer-promoting effect of low C1GALT1 expression in the constructed mouse model, is it tempting to speculate that complete deletion of the C1GALT1 gene may be harmful to tumor patients. More in-depth studies are required on the clinical significance of low C1GALT1 expression in cancer patients. With novel methods and the efforts of research scientists, the understanding of the impact of C1GALT1 expression on tumor patients will be enhanced. 


\section{Acknowledgements}

Not applicable.

\section{Funding}

This project was supported by the Natural Science Foundation of Hunan Province (grant no. 2019JJ80022), the Clinical Medical Technology Innovation Guidance Project of Hunan Province Technology Innovation Guidance Program (grant no. 2018SK51503).

\section{Availability of data and materials}

Data sharing is not applicable to this article, as no datasets were generated or analyzed during the current study.

\section{Authors' contributions}

TXia developed the concept for the study and drafted the manuscript. HX and TXiang reviewed and edited the manuscript. TXiang performed a literature search and selection. All authors read and approved the final manuscript. Data authentication is not applicable.

\section{Ethics approval and consent to participate}

Not applicable.

\section{Patient consent for publication}

Not applicable.

\section{Competing interests}

The authors declare that they have no competing interests.

\section{References}

1. Lis $\mathrm{H}$ and Sharon N: Protein glycosylation. Structural and functional aspects. Eur J Biochem 218: 1-27, 1993.

2. Spiro RG: Protein glycosylation: Nature, distribution, enzymatic formation, and disease implications of glycopeptide bonds. Glycobiology 12: 43R-56R, 2002.

3. Arike L and Hansson GC: The Densely O-Glycosylated MUC2 mucin protects the intestine and provides food for the commensal bacteria. J Mol Biol 428: 3221-3229, 2016.

4. Bennett EP, Mandel U, Clausen H, Gerken TA, Fritz TA and Tabak LA: Control of mucin-type O-glycosylation: A classification of the polypeptide GalNAc-transferase gene family. Glycobiology 22: 736-756, 2012.

5. Liu CH, Hu RH, Huang MJ, Lai IR, Chen CH, Lai HS, Wu YM and Huang MC: C1GALT1 promotes invasive phenotypes of hepatocellular carcinoma cells by modulating integrin $\beta 1$ glycosylation and activity. PLoS One 9: e94995, 2014.

6. Ju T and Cummings RD: A unique molecular chaperone Cosmc required for activity of the mammalian core 1 beta 3-galactosyltransferase. Proc Natl Acad Sci USA 99: 16613-16618, 2002.

7. Ju T, Otto VI and Cummings RD: The Tn antigen-structural simplicity and biological complexity. Angew Chem Int Ed Engl 50: 1770-1791, 2011

8. Galvan M, Tsuboi S, Fukuda M and Baum LG: Expression of a specific glycosyltransferase enzyme regulates $\mathrm{T}$ cell death mediated by galectin-1. J Biol Chem 275: 16730-16737, 2000.

9. Ju T, Cummings RD and Canfield WM: Purification, characterization, and subunit structure of rat core 1 Beta1,3-galactosyltransferase. J Biol Chem 277: 169-177, 2002.
10. Ju T, Brewer K, D'Souza A, Cummings RD and Canfield WM: Cloning and expression of human core 1 beta1,3-galactosyltransferase. J Biol Chem 277: 178-186, 2002.

11. Kudo T, Sato T, Hagiwara K, Kozuma Y, Yamaguchi $T$, Ikehara Y, Hamada M, Matsumoto K, Ema M, Murata S, et al: C1galt1-deficient mice exhibit thrombocytopenia due to abnormal terminal differentiation of megakaryocytes. Blood 122: 1649-1657, 2013.

12. Hanahan D and Weinberg RA: The hallmarks of cancer. Cell 100: $57-70,2000$.

13. Vajaria BN and Patel PS: Glycosylation: A hallmark of cancer? Glycoconj J 34: 147-156, 2017.

14. Munkley J and Elliott DJ: Hallmarks of glycosylation in cancer. Oncotarget 7: 35478-35489, 2016.

15. Liu F, Fu J, Bergstrom K, Shan X, McDaniel JM, McGee S, Bai X, Chen W and Xia L: Core 1-derived mucin-type O-glycosylation protects against spontaneous gastritis and gastric cancer. J Exp Med 217: e20182325, 2020.

16. Chou CH, Huang MJ, Chen CH, Shyu MK, Huang J, Hung JS, Huang CS and Huang MC: Up-regulation of C1GALT1 promotes breast cancer cell growth through MUC1-C signaling pathway. Oncotarget 6: 6123-6135, 2015.

17. Fu J, Gerhardt H, McDaniel JM, Xia B, Liu X, Ivanciu L, Ny A, Hermans K, Silasi-Mansat R, McGee S, et al: Endothelial cell O-glycan deficiency causes blood/lymphatic misconnections and consequent fatty liver disease in mice. J Clin Invest 118: 3725-3737, 2008.

18. Kuo TC, Wu MH, Yang SH, Chen ST, Hsu TW, Jhuang JY, Liao YY, Tien YW and Huang MC: C1GALT1 high expression is associated with poor survival of patients with pancreatic ductal adenocarcinoma and promotes cell invasiveness through integrin av. Oncogene 40: 1242-1254, 2021.

19. Lee PC, Chen ST, Kuo TC, Lin TC, Lin MC, Huang J, Hung JS, Hsu CL, Juan HF, Lee PH and Huang MC: C1GALT1 is associated with poor survival and promotes soluble Ephrin A1-mediated cell migration through activation of EPHA2 in gastric cancer. Oncogene 39: 2724-2740, 2020.

20. Lin MC, Chien PH, Wu HY, Chen ST, Juan HF, Lou PJ and Huang MC: C1GALT1 predicts poor prognosis and is a potential therapeutic target in head and neck cancer. Oncogene 37: 5780-5793, 2018.

21. Dong X, Luo Z, Wang Y, Meng L, Duan Q, Qiu L, Peng F and Shen L: Altered O-glycosylation is associated with inherent radioresistance and malignancy of human laryngeal carcinoma. Exp Cell Res 362: 302-310, 2018.

22. Chou $\mathrm{CH}$, Huang MJ, Liao YY, Chen $\mathrm{CH}$ and Huang MC: C1GALT1 seems to promote in vitro disease progression in ovarian cancer. Int J Gynecol Cancer 27: 863-871, 2017.

23. Wu YM, Liu CH, Huang MJ, Lai HS, Lee PH, Hu RH and Huang MC: C1GALT1 enhances proliferation of hepatocellular carcinoma cells via modulating MET glycosylation and dimerization. Cancer Res 73: 5580-5590, 2013.

24. Karsten U and Goletz S: What controls the expression of the core-1 (Thomsen-Friedenreich) glycotope on tumor cells? Biochemistry (Mosc) 80: 801-807, 2015.

25. Numa F, Tsunaga N, Michioka T, Nawata S, Ogata $\mathrm{H}$ and Kato $\mathrm{H}$ : Tissue expression of Sialyl Tn antigen in gynecologic tumors. J Obstet Gynaecol (Tokyo 1995) 21: 385-389, 1995.

26. Laack E, Nikbakht H, Peters A, Kugler C, Jasiewicz Y, Edler L, Hossfeld DK and Schumacher U: Lectin histochemistry of resected adenocarcinoma of the lung: Helix pomatia agglutinin binding is an independent prognostic factor. Am J Pathol 160: 1001-1008, 2002.

27. Konno A, Hoshino Y, Terashima S, Motoki R and Kawaguchi T: Carbohydrate expression profile of colorectal cancer cells is relevant to metastatic pattern and prognosis. Clin Exp Metastasis 19: 61-70, 2002.

28. Suzuki H, Moldoveanu Z, Hall S, Brown R, Vu HL, Novak L, Julian BA, Tomana M, Wyatt RJ, Edberg JC, et al: IgA1-secreting cell lines from patients with $\operatorname{IgA}$ nephropathy produce aberrantly glycosylated IgA1. J Clin Invest 118: 629-639, 2008.

29. Narimatsu Y, Kubota T, Furukawa S, Shimojima M, Iwasaki H, Tozawa Y, Tachibana K and Narimatsu H: Co-translational function of Cosmc, core 1 synthase specific molecular chaperone, revealed by a cell-free translation system. FEBS Lett 585: 1276-1280, 2011.

30. Alexander WS, Viney EM, Zhang JG, Metcalf D, Kauppi M, Hyland CD, Carpinelli MR, Stevenson W, Croker BA, Hilton AA, et al: Thrombocytopenia and kidney disease in mice with a mutation in the C1galt1 gene. Proc Natl Acad Sci USA 103: 16442-16447, 2006. 
31. Piller V, Piller F and Fukuda M: Biosynthesis of truncated $\mathrm{O}$-glycans in the $\mathrm{T}$ cell line Jurkat. Localization of O-glycan initiation. J Biol Chem 265: 9264-9271, 1990.

32. Ju T, Lanneau GS, Gautam T, Wang Y, Xia B, Stowell SR, Willard MT, Wang W, Xia JY, Zuna RE, et al: Human tumor antigens $\mathrm{Tn}$ and sialyl $\mathrm{Tn}$ arise from mutations in Cosmc. Cancer Res 68: 1636-1646, 2008.

33. Aryal RP, Ju T and Cummings RD: Tight complex formation between Cosmc chaperone and its specific client non-native T-synthase leads to enzyme activity and client-driven dissociation. J Biol Chem 287: 15317-15329, 2012.

34. Aryal RP, Ju T and Cummings RD: The endoplasmic reticulum chaperone Cosmc directly promotes in vitro folding of T-synthase. J Biol Chem 285: 2456-2462, 2010.

35. Ellis RJ: The molecular chaperone concept. Semin Cell Biol 1: $1-9,1990$.

36. Ju T, Aryal RP, Stowell CJ and Cummings RD: Regulation of protein O-glycosylation by the endoplasmic reticulum-localized molecular chaperone Cosmc. J Cell Biol 182: 531-542, 2008.

37. Ju T and Cummings RD: Protein glycosylation: Chaperone mutation in Tn syndrome. Nature 437: 1252, 2005.

38. Fidler IJ: The pathogenesis of cancer metastasis: The 'seed and soil' hypothesis revisited. Nat Rev Cancer 3: 453-458, 2003.

39. An G, Wei B, Xia B, McDaniel JM, Ju T, Cummings RD, Braun J and Xia L: Increased susceptibility to colitis and colorectal tumors in mice lacking core 3-derived O-glycans. J Exp Med 204 1417-1429, 2007

40. Guda K, Moinova H, He J, Jamison O, Ravi L, Natale L, Lutterbaugh $\mathrm{J}$, Lawrence $\mathrm{E}$, Lewis $\mathrm{S}$, Willson $\mathrm{JK}$, et al: Inactivating germ-line and somatic mutations in polypeptide $\mathrm{N}$-acetylgalactosaminyltransferase 12 in human colon cancers. Proc Natl Acad Sci USA 106: 12921-12925, 2009.

41. Brockhausen I: Pathways of O-glycan biosynthesis in cancer cells. Biochim Biophys Acta 1473: 67-95, 1999

42. Shin S, Jung Y, Uhm H, Song M, Son S, Goo J, Jeong C, Song JJ, Kim VN and Hohng S: Quantification of purified endogenous miRNAs with high sensitivity and specificity. Nat Commun 11: 6033, 2020.

43. Saliminejad K, Khorram Khorshid HR, Soleymani Fard S and Ghaffari SH: An overview of microRNAs: Biology, functions, therapeutics, and analysis methods. J Cell Physiol 234: 5451-5465, 2019.

44. Condrat CE, Thompson DC, Barbu MG, Bugnar OL, Boboc A, Cretoiu D, Suciu N, Cretoiu SM and Voinea SC: miRNAs as biomarkers in disease: Latest findings regarding their role in diagnosis and prognosis. Cells 9: 276, 2020.

45. Chen H, Xiao Z, Yu R, Wang Y, Xu R and Zhu X: miR-181d-5p-FOXP1 feedback loop modulates the progression of osteosarcoma. Biochem Biophys Res Commun 503: 1434-1441, 2018.

46. Wang $\mathrm{H}$, Wei $\mathrm{H}$, Wang $\mathrm{J}$, Li L, Chen A and Li Z: MicroRNA-181d-5p-containing exosomes derived from CAFs promote EMT by regulating CDX2/HOXA5 in breast cancer. Mol Ther Nucleic Acids 19: 654-667, 2020.

47. Gao LM, Zheng Y, Wang P, Zheng L, Zhang WL, Di Y, Chen LL, Yin XB, Tian Q, Shi SS and Xu SF: Tumor-suppressive effects of microRNA-181d-5p on non-small-cell lung cancer through the CDKN3-mediated Akt signaling pathway in vivo and in vitro. Am J Physiol Lung Cell Mol Physiol 316: L918-L933, 2019.

48. Dong X, Liu Y, Deng X, Shao J, Tian S, Chen S, Huang R, Lin Z, Chen C and Shen L: C1GALT1, negatively regulated by miR-181d-5p, promotes tumor progression via upregulating RAC1 in lung adenocarcinoma. Front Cell Dev Biol 9: 707970 , 2021.

49. Feng F, Liu H, Chen A, Xia Q, Zhao Y, Jin X and Huang J: miR-148-3p and miR-152-3p synergistically regulate prostate cancer progression via repressing KLF4. J Cell Biochem 120: 17228-17239, 2019.

50. Sun J, Tian X, Zhang J, Huang Y, Lin X, Chen L and Zhang S: Regulation of human glioma cell apoptosis and invasion by miR-152-3p through targeting DNMT1 and regulating NF2: MiR-152-3p regulate glioma cell apoptosis and invasion. J Exp Clin Cancer Res 36: 100, 2017.

51. Ma P, Li L, Liu F and Zhao Q: HNF1A-induced lncRNA HCG18 facilitates gastric cancer progression by upregulating DNAJB12 via miR-152-3p. Onco Targets Ther 13: 7641-7652, 2020.

52. Dong X, Chen C, Deng X, Liu Y, Duan Q, Peng Z, Luo Z and Shen L: A novel mechanism for C1GALT1 in the regulation of gastric cancer progression. Cell Biosci 11: 166, 2021.
53. Nguyen LK, Kholodenko BN and von Kriegsheim A: Rac1 and RhoA: Networks, loops and bistability. Small GTPases 9: 316-321, 2018.

54. Zou T, Mao X, Yin J, Li X, Chen J, Zhu T, Li Q, Zhou H and Liu Z: Emerging roles of RAC1 in treating lung cancer patients. Clin Genet 91: 520-528, 2017.

55. De P, Aske JC and Dey N: RAC1 Takes the lead in solid tumors. Cells 8: 382, 2019

56. Kazanietz MG and Caloca MJ: The Rac GTPase in Cancer: From old concepts to new paradigms. Cancer Res 77: 5445-5451, 2017.

57. Chen L, Zhang D, Ding T, Liu F, Xu X, Tian Y, Xiao J and Shen H: LncRNA NR2F2-AS1 upregulates Rac1 to increase cancer stemness in clear cell renal cell carcinoma. Cancer Biother Radiopharm 35: 301-306, 2020

58. Zeng Y, Ren M, Li Y, Chen C, Su J, Su B, Xia H, Liu F, Jiang H, Ling H, et al: Knockdown of RhoGDI2 represses human gastric cancer cell proliferation, invasion and drug resistance via the Rac1/Pak1/LIMK1 pathway. Cancer Lett 492: 136-146, 2020.

59. Chen HH, Yu HI, Cho WC and Tarn WY: DDX3 modulates cell adhesion and motility and cancer cell metastasis via Rac1-mediated signaling pathway. Oncogene 34: 2790-2800, 2015.

60. Hung JS, Huang J, Lin YC, Huang MJ, Lee PH, Lai HS, Liang JT and Huang MC: C1GALT1 overexpression promotes the invasive behavior of colon cancer cells through modifying O-glycosylation of FGFR2. Oncotarget 5: 2096-2106, 2014.

61. Liu SY, Shun CT, Hung KY, Juan HF, Hsu CL, Huang MC and Lai IR: Mucin glycosylating enzyme GALNT2 suppresses malignancy in gastric adenocarcinoma by reducing MET phosphorylation. Oncotarget 7: 11251-11262, 2016.

62. Wu YM, Liu CH, Hu RH, Huang MJ, Lee JJ, Chen CH, Huang J, Lai HS, Lee PH, Hsu WM, et al: Mucin glycosylating enzyme GALNT2 regulates the malignant character of hepatocellular carcinoma by modifying the EGF receptor. Cancer Res 71: 7270-7279, 2011

63. Huang MJ, Hu RH, Chou CH, Hsu CL, Liu YW, Huang J, Hung JS, Lai IR, Juan HF, Yu SL, et al: Knockdown of GALNT1 suppresses malignant phenotype of hepatocellular carcinoma by suppressing EGFR signaling. Oncotarget 6: 5650-5665, 2015.

64. Bradley CA, Salto-Tellez M, Laurent-Puig P, Bardelli A, Rolfo C, Tabernero J, Khawaja HA, Lawler M, Johnston PG and Van Schaeybroeck S; MErCuRIC consortium: Targeting c-MET in gastrointestinal tumours: Rationale, opportunities and challenges. Nat Rev Clin Oncol 14: 562-576, 2017.

65. Sierra JC, Asim M, Verriere TG, Piazuelo MB, Suarez G, Romero-Gallo J, Delgado AG, Wroblewski LE, Barry DP, Peek RM Jr, et al: Epidermal growth factor receptor inhibition downregulates-induced epithelial inflammatory responses, DNA damage and gastric carcinogenesis. Gut 67: 1247-1260, 2018.

66. Kania A and Klein R: Mechanisms of ephrin-Eph signalling in development, physiology and disease. Nat Rev Mol Cell Biol 17: 240-256, 2016

67. Xi HQ, Wu XS, Wei B and Chen L: Eph receptors and ephrins as targets for cancer therapy. J Cell Mol Med 16: 2894-2909, 2012.

68. Vaught D, Brantley-Sieders DM and Chen J: Eph receptors in breast cancer: Roles in tumor promotion and tumor suppression. Breast Cancer Res 10: 217, 2008.

69. Herath NI and Boyd AW: The role of Eph receptors and ephrin ligands in colorectal cancer. Int J Cancer 126: 2003-2011, 2010.

70. Lisle JE, Mertens-Walker I, Rutkowski R, Herington AC and Stephenson SA: Eph receptors and their ligands: Promising molecular biomarkers and therapeutic targets in prostate cancer. Biochim Biophys Acta 1835: 243-257, 2013.

71. Pasquale EB: Eph receptors and ephrins in cancer: Bidirectional signalling and beyond. Nat Rev Cancer 10: 165-180, 2010.

72. Boyd AW, Bartlett PF and Lackmann M: Therapeutic targeting of EPH receptors and their ligands. Nat Rev Drug Discov 13: 39-62, 2014.

73. Yuan WJ, Ge J, Chen ZK, Wu SB, Shen H, Yang P, Hu B, Zhang GW and Chen ZH: Over-expression of EphA2 and EphrinA-1 in human gastric adenocarcinoma and its prognostic value for postoperative patients. Dig Dis Sci 54: 2410-2417, 2009.

74. Nakamura R, Kataoka H, Sato N, Kanamori M, Ihara M, Igarashi $\mathrm{H}$, Ravshanov S, Wang YJ, Li ZY, Shimamura T, et al: EPHA2/EFNA1 expression in human gastric cancer. Cancer Sci 96: 42-47, 2005

75. Yuan W, Chen Z, Chen Z, Wu S, Guo J, Ge J, Yang P and Huang J: Silencing of EphA2 inhibits invasion of human gastric cancer SGC-7901 cells in vitro and in vivo. Neoplasma 59: 105-113, 2012. 
76. Zender L, Villanueva A, Tovar V, Sia D, Chiang DY and Llovet JM: Cancer gene discovery in hepatocellular carcinoma. J Hepatol 52: 921-929, 2010.

77. Marquardt JU, Galle PR and Teufel A: Molecular diagnosis and therapy of hepatocellular carcinoma (HCC): An emerging field for advanced technologies. J Hepatol 56: 267-275, 2012.

78. Herr P, Korniychuk G, Yamamoto Y, Grubisic K and Oelgeschläger M: Regulation of TGF-(beta) signalling by $\mathrm{N}$-acetylgalactosaminyltransferase-like 1 . Development 135 : 1813-1822, 2008

79. Kaposi-Novak P, Lee JS, Gòmez-Quiroz L, Coulouarn C, Factor VM and Thorgeirsson SS: Met-regulated expression signature defines a subset of human hepatocellular carcinomas with poor prognosis and aggressive phenotype. J Clin Invest 116 1582-1595, 2006.

80. Ke AW, Shi GM, Zhou J, Wu FZ, Ding ZB, Hu MY, Xu Y Song ZJ, Wang ZJ, Wu JC, et al: Role of overexpression of CD151 and/or c-Met in predicting prognosis of hepatocellular carcinoma. Hepatology 49: 491-503, 2009.

81. D'Errico A, Fiorentino M,Ponzetto A, Daikuhara Y, Tsubouchi H, Brechot C, Scoazec JY and Grigioni WF: Liver hepatocyte growth factor does not always correlate with hepatocellular proliferation in human liver lesions: Its specific receptor c-met does. Hepatology 24: 60-64, 1996.

82. Ma PC, Maulik G, Christensen J and Salgia R: c-Met: Structure, functions and potential for therapeutic inhibition. Cancer Metastasis Rev 22: 309-325, 2003.

83. Birchmeier C, Birchmeier W, Gherardi E and Vande Woude GF: Met, metastasis, motility and more. Nat Rev Mol Cell Biol 4 915-925, 2003

84. Casaletto JB and McClatchey AI: Spatial regulation of receptor tyrosine kinases in development and cancer. Nat Rev Cancer 12 387-400, 2012

85. Matsuda Y, Ueda J and Ishiwata T: Fibroblast growth factor receptor 2: Expression, roles, and potential as a novel molecula target for colorectal cancer. Patholog Res Int 2012: 574768 , 2012.

86. Hatch NE, Hudson M, Seto ML, Cunningham ML and Bothwell M: Intracellular retention, degradation, and signaling of glycosylation-deficient FGFR2 and craniosynostosis syndrome-associated FGFR2C278F. J Biol Chem 281: 27292-27305, 2006.

87. Schlessinger J: Ligand-induced, receptor-mediated dimerization and activation of EGF receptor. Cell 110: 669-672, 2002.

88. Leemans CR, Snijders PJF and Brakenhoff RH: The molecular landscape of head and neck cancer. Nat Rev Cancer 18: 269-282, 2018.

89. Tsai CH, Tzeng SF, Chao TK, Tsai CY, Yang YC, Lee MT, Hwang JJ, Chou YC, Tsai MH, Cha TL and Hsiao PW: Metastatic progression of prostate cancer is mediated by autonomous binding of Galectin-4-O-Glycan to cancer cells. Cancer Res 76 5756-5767, 2016.

90. Marcucci F, Bellone M, Caserta CA and Corti A: Pushing tumor cells towards a malignant phenotype: Stimuli from the microenvironment, intercellular communications and alternative roads Int J Cancer 135: 1265-1276, 2014.

91. Guo W and Giancotti FG: Integrin signalling during tumour progression. Nat Rev Mol Cell Biol 5: 816-826, 2004.

92. Mueller MM and Fusenig NE: Friends or foes-bipolar effects of the tumour stroma in cancer. Nat Rev Cancer 4: 839-849, 2004.

93. Hood JD and Cheresh DA: Role of integrins in cell invasion and migration. Nat Rev Cancer 2: 91-100, 2002.

94. Fransvea E, Mazzocca A, Antonaci S and Giannelli G: Targeting transforming growth factor (TGF)-betaRI inhibits activation of beta1 integrin and blocks vascular invasion in hepatocellular carcinoma. Hepatology 49: 839-850, 2009.

95. Yang C, Zeisberg M, Lively JC, Nyberg P, Afdhal $\mathrm{N}$ and Kalluri R: Integrin alpha1beta1 and alpha2beta1 are the key regulators of hepatocarcinoma cell invasion across the fibrotic matrix microenvironment. Cancer Res 63: 8312-8317, 2003.

96. Ke AW, Shi GM, Zhou J, Huang XY, Shi YH, Ding ZB, Wang XY, Devbhandari RP and Fan J: CD151 amplifies signaling by integrin $\alpha 6 \beta 1$ to PI3K and induces the epithelial-mesenchymal transition in HCC cells. Gastroenterology 140: 1629-1641.e15, 2011.

97. Lee SH, Hatakeyama S, Yu SY, Bao X, Ohyama C, Khoo KH, Fukuda MN and Fukuda M: Core3 O-glycan synthase suppresses tumor formation and metastasis of prostate carcinoma PC3 and LNCaP cells through down-regulation of alpha2beta1 integrin complex. J Biol Chem 284: 17157-17169, 2009.
98. Clément M, Rocher J, Loirand G and Le Pendu J: Expression of sialyl-Tn epitopes on beta1 integrin alters epithelial cell phenotype, proliferation and haptotaxis. J Cell Sci 117: 5059-5069, 2004

99. Liao WC, Chen $\mathrm{CH}$, Liu CH, Huang MJ, Chen CW, Hung JS Chou $\mathrm{CH}$, Chen $\mathrm{CH}$, Che MI, Chang HM, et al: Expression of GALNT2 in human extravillous trophoblasts and its suppressive role in trophoblast invasion. Placenta 33: 1005-1011, 2012.

100. Huang MC, Chen HY, Huang HC, Huang J, Liang JT, Shen TL, Lin NY, Ho CC, Cho IM and Hsu SM: C2GnT-M is downregulated in colorectal cancer and its re-expression causes growth inhibition of colon cancer cells. Oncogene 25: 3267-3276, 2006.

101. Park JH, Katagiri T, Chung S, Kijima K and Nakamura Y: Polypeptide N-acetylgalactosaminyltransferase 6 disrupts mammary acinar morphogenesis through O-glycosylation of fibronectin. Neoplasia 13: 320-326, 2011.

102.Zhang H, Meng F, Wu S, Kreike B, Sethi S, Chen W, Miller FR and Wu G: Engagement of I-branching \{beta\}-1, 6 - $\mathrm{N}$-acetylglucosaminyltransferase 2 in breast cancer metastasis and TGF- $\{$ beta\} signaling. Cancer Res 71: 4846-4856, 2011.

103. Chang $\mathrm{HH}$, Chen $\mathrm{CH}$, Chou $\mathrm{CH}$, Liao YF, Huang MJ, Chen YH, Wang WJ, Huang J, Hung JS, Ho WL, et al: $\beta-1,4-$ Galactosyltransferase III enhances invasive phenotypes via $\beta 1$-integrin and predicts poor prognosis in neuroblastoma. Clin Cancer Res 19: 1705-1716, 2013.

104. Seguin L, Desgrosellier JS, Weis SM and Cheresh DA: Integrins and cancer: Regulators of cancer stemness, metastasis, and drug resistance. Trends Cell Biol 25: 234-240, 2015.

105. Desgrosellier JS and Cheresh DA: Integrins in cancer: Biological implications and therapeutic opportunities. Nat Rev Cancer 10: 9-22, 2010

106. Marsico G, Russo L, Quondamatteo F and Pandit A: Glycosylation and integrin regulation in cancer. Trends Cancer 4: 537-552, 2018

107. Ju JA, Godet I, Ye IC, Byun J, Jayatilaka H, Lee SJ, Xiang L, Samanta D, Lee MH, Wu PH, et al: Hypoxia selectively enhances integrin $\alpha \beta$ receptor expression in breast cancer to promote metastasis. Mol Cancer Res 15: 723-734, 2017.

108. Li XQ, Lu JT, Tan CC, Wang QS and Feng YM: RUNX2 promotes breast cancer bone metastasis by increasing integrin a5-mediated colonization. Cancer Lett 380: 78-86, 2016.

109. Pantano F, Croset M, Driouch K, Bednarz-Knoll N, Iuliani M, Ribelli G, Bonnelye E, Wikman H, Geraci S, Bonin F, et al: Integrin alpha5 in human breast cancer is a mediator of bone metastasis and a therapeutic target for the treatment of osteolytic lesions. Oncogene 40: 1284-1299, 2021

110. Wang JF, Wang Y, Zhang SW, Chen YY, Qiu Y, Duan SY, Li BP and Chen JQ: Expression and prognostic analysis of integrins in gastric cancer. J Oncol 2020: 8862228, 2020.

111. Hakamada K: Cancer stroma-targeting therapy: A new tool for fighting pancreatic cancer? Ann Gastroenterol Surg 3: 120-121, 2019.

112. Guan JL: Role of focal adhesion kinase in integrin signaling. Int J Biochem Cell Biol 29: 1085-1096, 1997.

113. Mitra SK, Mikolon D, Molina JE, Hsia DA, Hanson DA, Chi A, Lim ST, Bernard-Trifilo JA, Ilic D, Stupack DG, et al: Intrinsic FAK activity and Y925 phosphorylation facilitate an angiogenic switch in tumors. Oncogene 25: 5969-5984, 2006.

114. Chen CH, Shyu MK, Wang SW, Chou CH, Huang MJ, Lin TC Chen ST, Lin HH and Huang MC: MUC20 promotes aggressive phenotypes of epithelial ovarian cancer cells via activation of the integrin $\beta 1$ pathway. Gynecol Oncol 140: 131-137, 2016.

115. Guan JL: Integrin signaling through FAK in the regulation of mammary stem cells and breast cancer. IUBMB Life 62 : 268-276, 2010

116. Nath S and Mukherjee P: MUC1: A multifaceted oncoprotein with a key role in cancer progression. Trends Mol Med 20: 332-342, 2014

117. Taylor-Papadimitriou J, Burchell JM, Plunkett T, Graham R, Correa I, Miles D and Smith M: MUC1 and the immunobiology of cancer. J Mammary Gland Biol Neoplasia 7: 209-221, 2002.

118. Kufe DW: Mucins in cancer: Function, prognosis and therapy Nat Rev Cancer 9: 874-885, 2009.

119. Apostolopoulos V, Stojanovska L and Gargosky SE: MUC1 (CD227): A multi-tasked molecule. Cell Mol Life Sci 72 4475-4500, 2015.

120. Chen CH, Wang SW, Chen CW, Huang MR, Hung JS, Huang HC, Lin HH, Chen RJ, Shyu MK and Huang MC: MUC20 overexpression predicts poor prognosis and enhances EGF-induced malignant phenotypes via activation of the EGFR-STAT3 pathway in endometrial cancer. Gynecol Oncol 128: 560-567, 2013. 
121. Chen CH, Hsiao SM, Chang TC, Wu WY and Lin HH: Clinical and urodynamic effects of baclofen in women with functional bladder outlet obstruction: Preliminary report. J Obstet Gynaecol Res 42: 560-565, 2016.

122. Pinho SS and Reis CA: Glycosylation in cancer: Mechanisms and clinical implications. Nat Rev Cancer 15: 540-555, 2015.

123. Razawi H, Kinlough CL, Staubach S, Poland PA, Rbaibi Y, Weisz OA, Hughey RP and Hanisch FG: Evidence for core 2 to core $1 \mathrm{O}$-glycan remodeling during the recycling of $\mathrm{MUC1}$. Glycobiology 23: 935-945, 2013.

124. Kufe DW: MUC1-C oncoprotein as a target in breast cancer: Activation of signaling pathways and therapeutic approaches Oncogene 32: 1073-1081, 2013.

125. Xu HL, Zhao X, Zhang KM, Tang W and Kokudo N: Inhibition of KL-6/MUC1 glycosylation limits aggressive progression of pancreatic cancer. World J Gastroenterol 20: 12171-12181, 2014

126. Wang Y, Liao X, Ye Q and Huang L: Clinic implication of MUC1 O-glycosylation and C1GALT1 in esophagus squamous cell carcinoma. Sci China Life Sci 61: 1389-1395, 2018.

127. Gendler SJ, Spicer AP, Lalani EN, Duhig T, Peat N, Burchell J, Pemberton L, Boshell M and Taylor-Papadimitriou J: Structure and biology of a carcinoma-associated mucin, MUC1. Am Rev Respir Dis 144 (Suppl 1): S42-S47, 1991.

128. Posey AD, Schwab RD, Boesteanu AC, Steentoft C, Mandel U, Engels B, Stone JD, Madsen TD, Schreiber K, Haines KM, et al Engineered CAR T cells targeting the cancer-associated Tn-glycoform of the membrane mucin MUC1 control adenocarcinoma. Immunity 44: 1444-1454, 2016.

129. Kato T, Ujiie H, Hatanaka KC, Nange A, Okumura A, Tsubame K, Naruchi K, Sato M, Kaga K, Matsuno Y, et al A novel Tn antigen epitope-recognizing antibody for MUC1 predicts clinical outcome in patients with primary lung adenocarcinoma. Oncol Lett 21: 202,2021.

130. Allen A, Hutton DA and Pearson JP: The MUC2 gene product: A human intestinal mucin. Int J Biochem Cell Biol 30: 797-801, 1998.

131. Tytgat KM, Büller HA, Opdam FJ, Kim YS, Einerhand AW and Dekker J: Biosynthesis of human colonic mucin: Muc2 is the prominent secretory mucin. Gastroenterology 107: 1352-1363, 1994.

132. van Klinken BJ, Einerhand AW, Duits LA, Makkink MK, Tytgat KM, Renes IB, Verburg M, Büller HA and Dekker J: Gastrointestinal expression and partial cDNA cloning of murine Muc2. Am J Physiol 276: G115-G124, 1999.

133. Johansson MEV, Phillipson M, Petersson J, Velcich A, Holm L and Hansson GC: The inner of the two Muc2 mucin-dependent mucus layers in colon is devoid of bacteria. Proc Natl Acad Sci USA 105: 15064-15069, 2008

134. Bergstrom K, Fu J, Johansson ME, Liu X, Gao N, Wu Q, Song J, McDaniel JM, McGee S, Chen W, et al: Core 1- and 3 -derived $\mathrm{O}$-glycans collectively maintain the colonic mucus barrier and protect against spontaneous colitis in mice. Mucosal Immunol 10: 91-103, 2017

135. Bergstrom K, Liu X, Zhao Y, Gao N, Wu Q, Song K, Cui Y, Li Y, McDaniel JM, McGee S, et al: Defective intestinal Mucin-type O-Glycosylation causes spontaneous colitis-associated cancer in mice. Gastroenterology 151: 152-164.e11, 2016.

136. Gao N, Bergstrom K, Fu J, Xie B, Chen W and Xia L: Loss of intestinal O-glycans promotes spontaneous duodenal tumors. Am J Physiol Gastrointest Liver Physiol 311: G74-G83, 2016.

137. Johansson MEV, Sjövall H and Hansson GC: The gastrointestinal mucus system in health and disease. Nat Rev Gastroenterol Hepatol 10: 352-361, 2013

138. Chugh S, Barkeer S, Rachagani S, Nimmakayala RK, Perumal N, Pothuraju R, Atri P, Mahapatra S, Thapa I, Talmon GA, et al: Disruption of C1galt1 Gene promotes development and metastasis of pancreatic adenocarcinomas in mice. Gastroenterology 155 : $1608-1624,2018$
139. da Fonseca LM, da Silva VA, Freire-de-Lima L, Previato JO, Mendonça-Previato L and Capella MAM: Glycosylation in Cancer: Interplay between Multidrug resistance and Epithelial-to-Mesenchymal Transition? Front Oncol 6: 158, 2016.

140. Ma H, Miao X, Ma Q, Zheng W, Zhou H and Jia L: Functional roles of glycogene and N-glycan in multidrug resistance of human breast cancer cells. IUBMB Life 65: 409-422, 2013.

141. Wu J, Qin H, Li T, Cheng K, Dong J, Tian M, Chai N, Guo H, Li J, You X, et al: Characterization of site-specific glycosylation of secreted proteins associated with multi-drug resistance of gastric cancer. Oncotarget 7: 25315-25327, 2016.

142. Huang C, Huang M, Chen W, Zhu W, Meng H, Guo L, Wei T and Zhang J: N-acetylglucosaminyltransferase $\mathrm{V}$ modulates radiosensitivity and migration of small cell lung cancer through epithelial-mesenchymal transition. FEBS J 282: 4295-4306, 2015.

143. Zhuo E, He J, Wei T, Zhu W, Meng H, Li Y, Guo L and Zhang J: Down-regulation of GnT-V enhances nasopharyngeal carcinoma cell CNE-2 radiosensitivity in vitro and in vivo. Biochem Biophys Res Commun 424: 554-562, 2012.

144.Park JJ and Lee M: Increasing the $\alpha 2,6$ sialylation of glycoproteins may contribute to metastatic spread and therapeutic resistance in colorectal cancer. Gut Liver 7: 629-641, 2013.

145. Shen L, Dong XX, Wu JB, Qiu L, Duan QW and Luo ZG: Radiosensitisation of human glioma cells by inhibition of 31,6-GlcNAc branched N-glycans. Tumour Biol 37: 4909-4918, 2016.

146. Zhang C, Deng X, Qiu L, Peng F, Geng S, Shen L and Luo Z: Knockdown of C1GalT1 inhibits radioresistance of human esophageal cancer cells through modifying $\beta 1$-integrin glycosylation. J Cancer 9: 2666-2677, 2018

147. Moncharmont C, Levy A, Guy JB, Falk AT, Guilbert M, Trone JC, Alphonse G, Gilormini M, Ardail D, Toillon RA, et al: Radiation-enhanced cell migration/invasion process: A review. Crit Rev Oncol Hematol 92: 133-142, 2014.

148. Paquette B, Therriault H, Desmarais G, Wagner R, Royer R and Bujold R: Radiation-enhancement of MDA-MB-231 breast cancer cell invasion prevented by a cyclooxygenase- 2 inhibitor. Br J Cancer 105: 534-541, 2011.

149. Qian LW, Mizumoto K, Urashima T, Nagai E, Maehara N, Sato N, Nakajima M and Tanaka M: Radiation-induced increase in invasive potential of human pancreatic cancer cells and its blockade by a matrix metalloproteinase inhibitor, CGS27023. Clin Cancer Res 8: 1223-1227, 2002.

150. Wu J, Li Y, Dang YZ, Gao HX, Jiang JL and Chen ZN: HAb18G/CD147 promotes radioresistance in hepatocellular carcinoma cells: A potential role for integrin $\beta 1$ signaling. Mol Cancer Ther 14: 553-563, 2015.

151. Aftab BT, Dobromilskaya I, Liu JO and Rudin CM: Itraconazole inhibits angiogenesis and tumor growth in non-small cell lung cancer. Cancer Res 71: 6764-6772, 2011.

152. Kim J, Tang JY, Gong R, Kim J, Lee JJ, Clemons KV, Chong CR, Chang KS, Fereshteh M, GardnerD, etal: Itraconazole, a commonly used antifungal that inhibits Hedgehog pathway activity and cancer growth. Cancer Cell 17: 388-399, 2010.

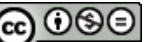

This work is licensed under a Creative Commons Attribution-NonCommercial-NoDerivatives 4.0 International (CC BY-NC-ND 4.0) License. 